\title{
Management of sustainable development of territories
}

\author{
Ostanina Ulyana
}

Ural State University of Economics, 8 Marta/Narodnoy Voli St. 62/45, 620144 Yekaterinburg, Russia

\begin{abstract}
The theoretical aspect of managing sustainable development of territories is considered. The analysis of management of sustainable development of territories is carried out on the example of the Sverdlovsk region.
\end{abstract}

\section{Introduction}

Ensuring sustainable development is one of the most pressing concerns of the world community. This problem arose in the second half of the twentieth century and has not yet been resolved, despite the efforts of scientists, politicians and practitioners of all countries. The main idea of the presented article is to assess the success of achieving the Sustainable Development Goals in the Sverdlovsk Region.

Currently, the essence of sustainable development has expanded significantly, at present, the model of sustainable development provides for the harmonization of social, economic and environmental components, aimed at meeting the needs of present and future generations.

The purpose of this study is to analyze the management of sustainable development of territories using the example of the Sverdlovsk region.

The object of research is the Sverdlovsk region.

\section{Materials and methods}

Analysis of scientific literature on the topic of research, comparison, deduction, analysis of statistical data of the Sverdlovsk region.

\section{Results and discussion}

The problem of sustainable development has been of concern to the world community for more than a decade. Its theoretical foundations were laid by the Russian scientist V.I. Vernadsky. The system of scientific views of the scientist, set out in his works on the development of the biosphere [1], in fact, anticipated the awareness of global problems by the general public. 
Initially, the concept of "sustainable development" related mainly to the field of ecology [2]. However, the modern interpretation of sustainable development significantly expands its essence and the range of tasks to be solved [3]. In general terms, sustainable development should be understood as development based on the harmonization of economic, social and environmental subsystems, aimed at finding ways to meet the needs of present and future generations. The list of tasks includes accelerating economic growth and changing its quality; meet the basic needs of the population; constant population growth; preservation and strengthening of the resource base of the territories, etc. [4].

The Decree of the President of the Russian Federation of 01.04.1996 No. 440 "On the Concept of the Transition of the Russian Federation to Sustainable Development" emphasizes that "sustainable development of the country is possible only in the case of sustainable development of all its constituent territories" [5]. This is possible on the basis of the formation of an effective spatial structure of the economy while maintaining a balance of interests of all constituent entities of the Russian Federation and taking into account local characteristics.

The stability of the socio-economic development of territories depends on many factors and conditions, both global and internal, specific to each country and even each territory. One of the most important internal factors is the current management system, which includes tools and methods of influencing socio-economic processes in the territory by the authorities of different levels in order to achieve the sustainability of its development. In other words, solving the problems of sustainable development of the country and its territories requires active actions on the part of the authorities and the administration, carried out within the framework of the socio-economic policy implemented at the federal, regional and local levels.

The sustainable development of the region largely depends on the functioning of the main industries on its territory, which should also be quite stable. Manufacturing sustainability refers to its ability to withstand and prevent impacts that can disrupt business processes. Sustainable development can be understood as production that ensures the production of the required range of consumer goods at the lowest cost, with the efficient use of production factors and at the required time, as well as with the least negative impact on the environment.

The sustainability of the reproduction of the territorial and economic complex of the region is determined by ensuring the continuous maintenance of economic stability or growth at minimal costs, economic and social security, environmental compatibility of the technologies used, contributing to a more complete satisfaction of the material and spiritual needs of the population. region. The sustainability of the development of the territory depends on the level of self-sufficiency, self-financing, self-sufficiency and economic independence. By the level of self-sufficiency, we mean the self-sufficiency of the territory with economic resources, which allows us to guarantee a stable and positive trade balance in the export and import of the region's products, including in foreign economic relations.

The stages of Russia's transition to sustainable development are shown in Figure 1. 


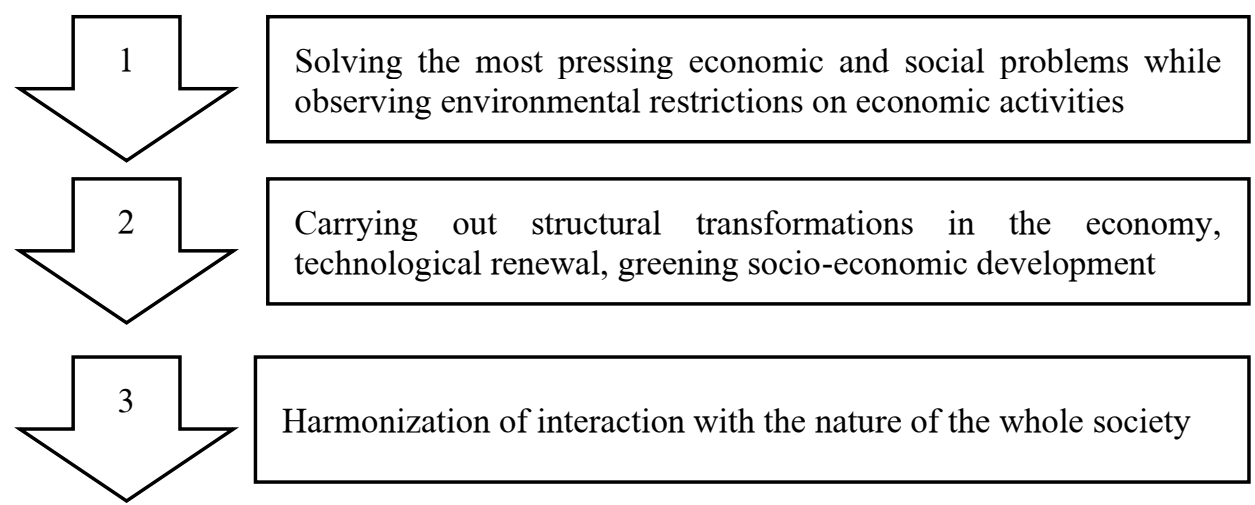

Fig. 1. Stages of Russia's transition to sustainable development

Currently, the Ministry of Economic Development of the Russian Federation is working on a new tool for the integrated development of territories aimed at creating legal and economic conditions for the implementation of landmark pilot urban projects.

The new instrument is being developed as part of a nationwide economic recovery plan.

"If the new mechanism is implemented, regional authorities will receive an effective tool for redeveloping urban centers, including planning social and engineering infrastructure, as well as the opportunity to attract investors at different stages of the project," said Russian Minister of Economic Development Maxim Reshetnikov during his working visit to Krasnodar.

The tool is aimed at transforming depressed urban areas and public spaces, as well as stimulating the renovation of "dilapidated" housing stock and increasing the share of quality offers in the real estate market. One of the advantages of the new mechanism should be a significant reduction in the terms of urban planning preparation of construction.

Currently, the Sverdlovsk Region has the Law of the Sverdlovsk Region "On the Strategy of Social and Economic Development of the Sverdlovsk Region for 2016-2030".

The Sverdlovsk Region is one of the largest and most industrially developed regions of the Russian Federation. The geographical position allows the Sverdlovsk region to play an important role not only in the development of national, but also Euro-Asian transport links.

The main factor of natural resources for the development of the region is, first of all, the mineral component, which largely determines the nature of the production potential of the region.

The industrial complex of the Sverdlovsk region is one of the largest in the country. The presence of various minerals in the region has determined the development of heavy industry on its territory, the main of which are metallurgy of non-ferrous and ferrous metals, mechanical engineering and metalworking, as well as electric power. There is a scientific potential, a developed transport network and other engineering infrastructure.

In Figure 2, we present the population of the Sverdlovsk region for 2015-2019. 


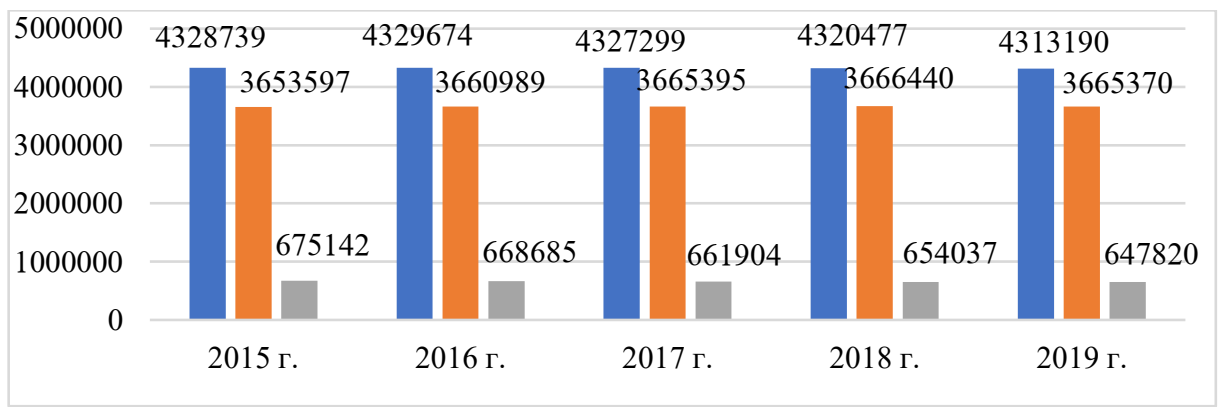

Fig. 2. The population of the Sverdlovsk region for 2015-2019, people

As follows from the data presented in the figure, for the analyzed period as a whole, the population of the region is decreasing. At the same time, negative changes have occurred both in the urban population and in the rural population.

The industrial production index in the Sverdlovsk region is presented in Figure 3.

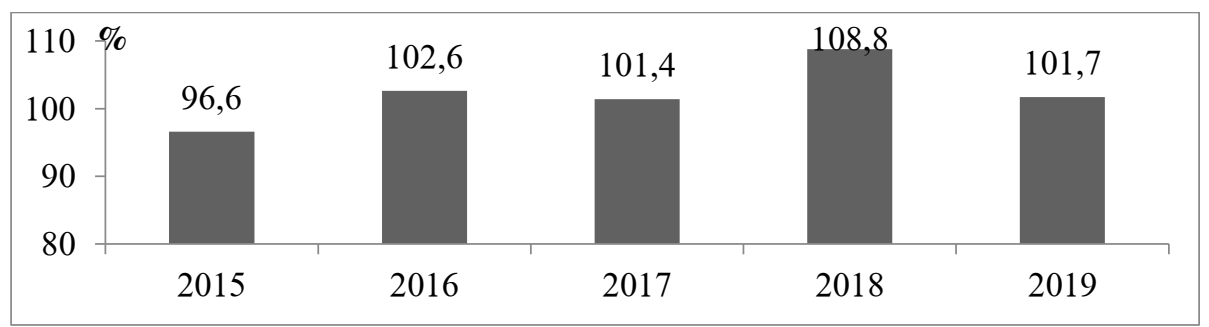

Fig. 3. Industrial production index in the Sverdlovsk region

The industrial production index in the Sverdlovsk region in 2019 compared to 2018 decreased by 6.5 points and amounted to $101.70 \%$. The highest level of the industrial production index was observed in 2018 and amounted to $108.80 \%$.

In the Sverdlovsk region, the production index by type of activity "Supply of electricity, gas and steam; air conditioning "in 2019 compared to 2018 amounted to $102.9 \%$. Electricity production increased in physical terms by $2.6 \%$ [6].

Production index by type of activity "Water supply; sewerage, waste collection and disposal, activities to eliminate pollution "in the Sverdlovsk region in 2019 amounted to $98.5 \%$, which indicates a decrease in business activity in this area.

According to Sverdlovskstat, residential buildings with a total area of 1,190.1 thousand square meters were commissioned in 2019 at the expense of all sources of financing. meters, or $106.4 \%$ to the level of 2018 [6].

The retail trade turnover in the Sverdlovsk region by $97.2 \%$ was formed by trading organizations and individual entrepreneurs operating outside the markets; the share of sales of goods in retail markets and fairs was $2.8 \%$ [6].

Accrued average monthly nominal wage per employee in the Sverdlovsk region in 2019 amounted to $40,899.6$ rubles and increased compared to 2018 by $6.7 \%$, real wages adjusted for the consumer price index increased by $1.7 \%[6]$. 
The accrued average monthly nominal wage per employee in the Sverdlovsk Region in 2019 amounted to $40,899.6$ rubles and increased compared to 2018 by $6.7 \%$, real wages, adjusted for the consumer price index, increased by $1.7 \%$ (figure 4 ).

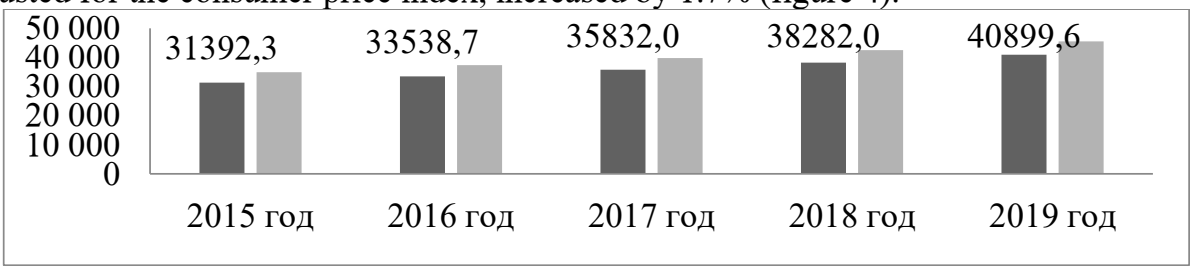

Fig. 4. Dynamics of changes in the salary of one employee in the Sverdlovsk region, rubles

The Sverdlovsk Region ranks fifth in terms of the constituent entities of the Russian Federation in terms of the volume of internal expenditures on R\&D in 2019.And, as follows from the data presented, the costs of enterprises on R\&D tend to grow.

Unemployment rates in the Sverdlovsk region are shown in Figure 5.

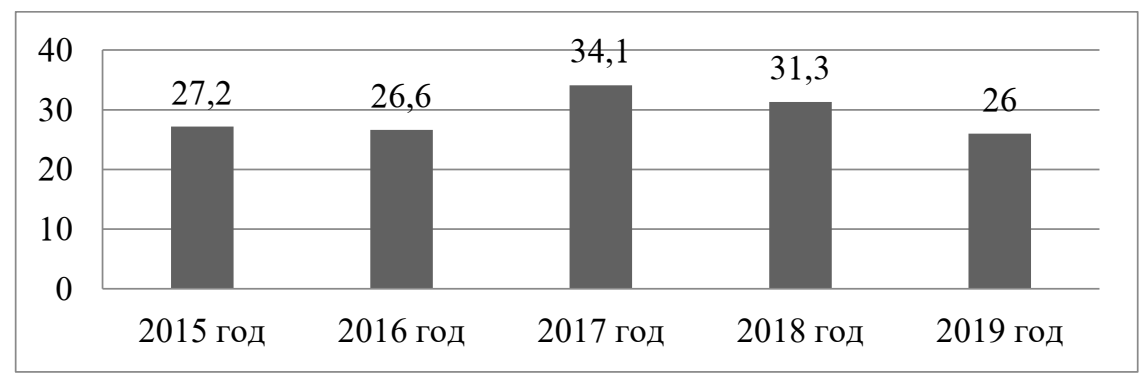

Fig. 5. Unemployment rates in the Sverdlovsk region for 2015-2019

As follows from the data presented, in the Sverdlovsk region in 2018-2019. the unemployment situation has improved somewhat. In 2019, 26.0 thousand unemployed were officially registered with state employment services, and the level of registered unemployment was $1.2 \%$ of the labor force.

The average monthly volume of paid services to the population per one resident of the Sverdlovsk region in 2019 amounted to 7,867 rubles, of which household services - 697 rubles. The structure of paid services provided to the population in 2019 in the Sverdlovsk region is shown in Figure 6.

The retail turnover in the Sverdlovsk region in 2019 amounted, according to Sverdlovskstat, to 867.7 billion rubles, or $101.5 \%$ in comparable prices to the level of 2018 (Figure 7).

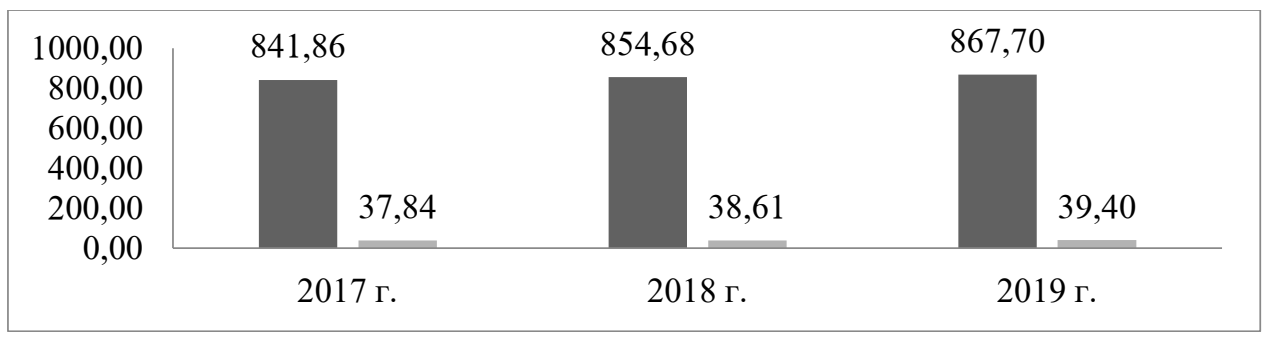

Fig. 7. Turnover of retail trade and public catering in the Sverdlovsk region for 2017-2019, billion rubles 
Public catering turnover in 2019 amounted to 39.4 billion rubles, which in comparable prices is $102 \%$ to the level of 2018 [6].

There are also other facts that indicate that a number of the most pressing issues have not been resolved for many years. Therefore, it is premature to talk about sustainable development of the region. Undoubtedly, the authorities at various levels are making efforts to correct the situation and bring the territories onto the trajectory of sustainable development. The main instrument designed to ensure the achievement of sustainable development goals are government programs [8].

Another tool widely used by regional government and local government bodies to solve the problems of territories is the project approach.

\section{Conclusions}

Therefore, today, positive changes that increase the competitiveness of regions in the long term are inextricably linked with the implementation of the concept of sustainable development on their territory. The current economic situation in most of them creates serious problems for its implementation, and only thanks to the joint efforts of the federal center, local authorities, business and civil society institutions, we can achieve success.

Local governments should be more active in implementing strategic planning, which is widely used by regions, counties and large cities. As for municipalities at the settlement level, only a few have development strategies. A long-term vision of your future is the key to sustainable development of territories. Thus, the task of society's transition to a sustainable development model has not yet lost its relevance [9].

One of the reasons is the dynamism and unpredictability of factors that determine the sustainability of socio-economic development. First of all, this concerns external factors and challenges, including economic crises, the struggle of countries for resources and sales markets, the structural transformation of the economy, including as a result of its digitalization [10], etc.

For example, at the end of 2019, almost no one could have foreseen the appearance of the coronavirus infection COVID-19, which led to the reduction of entire sectors of the economy; aggravation of the struggle for oil markets, which led to a drop in world oil prices; the current economic crisis and a number of negative processes that followed. Of course, these factors reduce the resilience of countries, individual regions and municipalities.

However, many problems of Russian territories are a consequence of the negative influence of internal factors, therefore, when choosing ways to achieve sustainable development of territories, it is necessary to focus on the possibility of influencing internal factors through the instruments of regional socio-economic policy.

\section{References}

1. G. Gagarina, L. Chainikova, L. Arkhipova, Federalism, 69 (2019)

2. V.A. Ivanov, Problems of territory development, 104 (2019)

3. E. Karpunina, The Economist, 150 (2020)

4. T.V. Uskova, Territory development problems, 106 (2020)

5. Decree of the President of the Russian Federation of 01.04.1996 No. 440 "On the Concept of the Transition of the Russian Federation to Sustainable Development"

6. Office of the Federal State Statistics Service for the Sverdlovsk Region 
7. Socio-economic situation of the Ural Federal District in 2019

8. T.V. Uskova, N.V. Voroshilov, Problems of territory development, 104 (2019)

9. A.D. Ursul, T.A. Ursul Vectors, Philosophical Sciences, 149 (2017)

10. E.B. Shulepov, K.A. Zadumkin, How to write and implement a rural settlement strategy, 48 (2018) 